\title{
Reduction of antimicrobial use and resistance needs sectoral- collaborations with a One Health approach: perspectives from Asia
}

\author{
Hung Nguyen-Viet $\cdot$ Suwit Chotinun $\cdot$ Esther Schelling $\cdot$ Winda Widyastuti $\cdot$ \\ Nguyen Viet Khong • Manish Kakkar - Arlyne Beeche $\cdot$ Fang Jing • \\ Boualam Khamlome $\cdot$ Sothyra Tum $\cdot$ Wiku Adisasmito
}

Received: 29 November 2016/ Accepted: 30 November 2016/Published online: 9 December 2016 (c) Swiss School of Public Health (SSPH+) 2016

The misuse of antimicrobials in human health and animal production, and concomitant increase in antimicrobial resistance (AMR), is recognized as an emergent global problem, affecting human and animal health (Lancet 2015) and imposing social and economic burdens on society. It is estimated that globally, by 2050, 10 million people will die annually due to AMR. In Asia, the use of antimicrobials and resultant AMR is not well characterized, although some studies have attempted to estimate the amount of antibiotic use. Asia's population represents a large portion of this global cohort, with intensive agriculture production

This editorial is part of the supplement "Health and social determinants of health in Vietnam: local evidence and international implications".

\footnotetext{
H. Nguyen-Viet ( $\square)$

International Livestock Research Institute, Hanoi, Vietnam

e-mail: h.nguyen@cgiar.org

H. Nguyen-Viet

Hanoi University of Public Health, Hanoi, Vietnam

S. Chotinun

Faculty of Veterinary Medicine, Chiang Mai University,

Chiang Mai, Thailand

e-mail: suwitchotinun@gmail.com

E. Schelling

Swiss Tropical and Public Health Institute, Basel, Switzerland

e-mail: esther.schelling@unibas.ch

E. Schelling

University of Basel, Basel, Switzerland

W. Widyastuti

Center for Indonesian Veterinary Analytical Studies (CIVAS),

Bogor, Indonesia

e-mail: winda_digna@yahoo.co.id
}

systems, making it a large and significant consumer and user of antimicrobials. In Vietnam, it is estimated that over 2000 tonnes of antimicrobials are used for feed production for chicken and pig annually (Van Cuong et al. 2016). Three countries (Vietnam, Thailand and China) use onethird of antimicrobials worldwide in livestock production (Van Boeckel et al. 2015). It may therefore not be less surprising that colistin-resistant Escherichia coli were first isolated from food and described in China and a second report is from Vietnam (Malhotra-Kumar et al. 2016).

In the absence of stringent policies, overuse of antibiotics in human medicine and livestock production and aquaculture (for disease prevention and treatment, and growth promotion), significant antimicrobial use (AMU) and AMR issues arise (O’Neill 2016). Drivers of antibiotic

\section{N. V. Khong}

National Institute of Veterinary Research (NIVR), Hanoi,

Vietnam

e-mail: nguyenvietkhong@yahoo.com

M. Kakkar

Public Health Foundation of India (PHFI), New Delhi, India e-mail: manish.kakkar@phfi.org

A. Beeche

International Development Research Center (IDRC), New Delhi, India

\section{F. Jing}

Institute for Health Sciences, Kunming Medical University,

Kunming, China

e-mail: fangjing07@126.com

\section{B. Khamlome}

Department of Disease Control, Ministry of Health,

Vientiane, Lao People's Democratic Republic

e-mail: drboualamkhamlome@gmail.com 
use and resistance at the community level include selfdiagnosis, buying antibiotics without prescription, and antibiotic use. On an institutional level, such as hospitals, inadequate infection control and lack of knowledge about appropriate antibiotic use are compounding factors. The steep increase in AMR endangers the effectiveness of antibiotic treatment, escalating the burden of infectious diseases. These burdens create a justifiable need for studies and approaches to assess and characterize AMR-related issues. In the agricultural sector, the misuse of antimicrobials can lead to unnecessary animal and environmental health issues as well as economic losses. For example, exports of Asian aquacultural products to US and EU markets, which have stringent food standards, are being rejected where antibiotic residues are detected. It is vital that Asia tackles these AMU and AMR issues. While initiatives to revise policies have been taken up at national and regional levels, to date few activities or programs to implement these policies are in place. There is wide recognition that the human health and agriculture sectors need to contribute. It is no longer a question 'if' they should both, but the focus is on 'when' and 'how'.

AMR is a "One Health/Ecohealth" topic where animal, human and environment health sectors can work together to develop integrated surveillance and response systems. One Health is defined as action that leads to added value in terms of better health and well-being for humans and animals, financial savings, and improved environmental/ ecosystems services (Zinsstag et al. 2015); a relevant and cogent framework to address AMR and AMU issues.

An early example of the One Health approach is the AMR investigation into the human and animal sectors in Southeast Asia, undertaken by a consortium of Ecohealth researchers. This initiative was implemented under the Asia Partnership on Emerging Infectious Disease Research (APEIR), a research network comprised of researchers, practitioners and senior government officials from Cambodia, China, Laos, Indonesia, Thailand and Vietnam. The overarching research objective was to develop a strategy for prudent AMU practices to control AMR in humans, animals and environment health. In Thailand, E. coli resistant to ampicillin, chlorotetracycline, and enrofloxacine were isolated from rectal and stool samples from farmers. In Indonesia, E. coli resistant to ampicillin and tetracycline were isolated from pig samples. Exploration of

\section{S. Tum}

Department of Animal Health and Production, National

Veterinary Research Institute, Phnom Penh, Cambodia

e-mail: sothyratum@gmail.com

W. Adisasmito

University of Indonesia, Jakarta, Indonesia

e-mail: wiku.adisasmito@gmail.com
AMR cross-transmission between animals and humans is important in the Asia region, considering the potential interplay of food chain or animal-human-animal exposure (APEIR 2016), and the environment (such as downstream multi-purpose wastewater and sludge used as fertilizers) enlarge this interface.

Regional collaboration and exchange on AMR and AMU is equally important as collaboration between sectors (no country and no sector can do it alone). It is also important to expand research networks from Southeast Asia to South Asia as these two regions have compelling reasons to work together. This collaboration will strengthen the research partnerships among and between institutions cross-regionally and offer opportunities to learn from each other.

As a path forward, it is important to better characterize AMU and AMR in Asia, and develop research and intervention programs to inform a unified strategy for the rational use of antibiotics that reduces AMR in agriculture and public health. We propose the development of an integrated AMR surveillance system using a One Health approach to understand the AMU and AMR situation in Asia's agriculture and public health sectors, and identify priority intervention hot spots. The Canadian Integrated Program for AMR Surveillance can serve as a program exemplar with adaptations to Asia (PHAC 2016). Deeper understandings of how AMR and AMU contribute to economic development; impacts on health, environment and the economy; and AMR transmission mechanisms are needed. "One Health/Ecohealth" interventions to reduce AMR-related human, animal and environmental burdens need to be developed, implemented and monitored. This requires the participation of key stakeholders from the private-, policy- and health-sectors to work collaboratively to reduce these burdens, advance peoples' health, and grow robust economies.

Acknowledgements We thank the International Development Research Center (IDRC) for funding the regional APEIR meeting in Bali in October 2016 to develop this editorial. We gratefully acknowledge Julie Hood, a Canada VWB/VSF volunteer, for an English language review of this editorial.

\section{References}

APEIR (2016) APEIR activities. http://www.apeir.net/resources/ current-research. Accessed 29 Dec 2016

Lancet (2015) Lancet series on antimicrobials. http://www.thelancet. com/series/antimicrobials-access-and-sustainable-effectiveness. Accessed 28 Dec 2016

Malhotra-Kumar S, Xavier BB, Das AJ, Lammens C, Hoang HT, Pham NT, Goossens H (2016) Colistin-resistant Escherichia coli harbouring mcr-1 isolated from food animals in Hanoi, Vietnam. Lancet Infect Dis 16:286-287. doi:10.1016/s1473-3099(16) 00014-1 
O’Neill J (2016) Tackling drug-resistant infections globally: final report and recommendations. The review on antimicrobial resistance. https://amr-review.org/sites/default/files/160518_ Final\%20paper_with\%20cover.pdf. Accessed 29 Nov 2016

PHAC (2016) Public Health Agency of Canada-Canadian integrated program for antimicrobial resistance surveillance (CIPARS). http://www.phac-aspc.gc.ca/cipars-picra/index-eng.php. Accessed 29 Dec 2016

Van Boeckel TP et al (2015) Global trends in antimicrobial use in food animals. Proc Natl Acad Sci USA 112:5649-5654. doi:10. 1073/pnas. 1503141112
Van Cuong N, Nhung NT, Nghia NH, Mai Hoa NT, Trung NV, Thwaites G, Carrique-Mas J (2016) Antimicrobial consumption in medicated feeds in Vietnamese pig and poultry production. EcoHealth 13:490-498. doi:10.1007/s10393-016-1130-z

Zinsstag J, Schelling E, Waltner-Toews D, Whittaker M, Tanner M (2015) One Health: the theory and practice of integrated health approaches. CABI, Wallingford, United Kingdom 